\title{
From perceived polarization of immigration attitudes to collective action
}

\author{
Antoine Roblain $^{\mathrm{a}}{ }^{*}$, Eva G.T. Green ${ }^{\mathrm{b}}$ \\ ${ }^{a}$ Université Libre de Bruxelles, Belgium \\ ${ }^{\mathrm{b}}$ University of Lausanne, Switzerland
}

\section{A R T I C L E I N F O}

\section{Keywords:}

Collective action

Attitudes toward immigration

Polarization

\begin{abstract}
A B S T R A C T
In the context where immigration divides the political space of Western societies, perceived social polarization as an explanation of collective action is surprisingly understudied in contemporary social psychology. We hypothesize that the more people perceive polarization, the more they will engage in collective action in line with their attitudes. Moreover, this effect should be explained by two interrelated factors: identification and perceived efficacy. Perceived polarization should shape how important immigration attitudes are for individuals' self-definition and thereby believing oneself capable of making a change, which in turn triggers collective action. To test our predictions, we conducted three studies (Studies 1 and 2 were correlational and Study 3 experimental) among mobilized and non-mobilized samples in two countries (i.e., Belgium and Switzerland). Results partially support our predictions that perceived social polarization on immigration issues relates to engaging in collective action. Indirect effect analyses revealed the predominant role of identity dynamics in the social psychological processes linked to perceiving polarization. These results provide potential explanations to the strong mobilization that emerged since 2015 following the so-called migrant crisis. Implications of our findings for collective action literature are discussed.
\end{abstract}

\section{Introduction}

The so-called European migrant crisis of 2015 triggered polarization both within and between nations. On the one hand, political discourse and debate in traditional and social media have widely broadcast negative representations of migrants and refugees. Citizens' anti-migration actions have also grown or at least become more visible. On the other hand, public activism for refugees' rights has increased (della Porta, 2018; Simsa, 2017). According to Kriesi et al. (2006), the current globalization process has led to a new political cleavage in which immigration issues are central. In the current paper, we examine how perceived polarization of immigration attitudes shapes collective action.

In his seminal work, Allport (1954) highlighted that the perception of social reality has a considerable impact on cognitions, attitudes and behaviours. Other pioneering work in social psychology, such as Social Judgment Theory (Sherif \& Hovland, 1961), also supports the idea that our attitudes towards an issue are affected by our perception of others' positions. Research has indeed amply demonstrated social influence exerted by an actual or perceived societal context, notably showing that exclusive (vs inclusive)

\footnotetext{
* Corresponding author at: Center for Social and Cultural Psychology CeSCuP, Université Libre de Bruxelles, 50 avenue F. D. Roosevelt CP122, 1050 Bruxelles, Belgium.

E-mail address: aroblain@ulb.ac.be (A. Roblain).
} 
normative climates shape individuals' attitudes toward immigration (e.g., Falomir-Pichastor, Muñoz-Rojas, Invernizzi, \& Mugny, 2004; Fasel, Green, \& Sarrasin, 2013; Visintin, Green, Falomir-Pichastor, \& Berent, 2019). While polarization on immigration issues is well documented (e.g., Kriesi et al., 2006; Strijbis, Helmer, \& de Wilde, 2018), until now, social psychological investigations have mainly focused on the determinants of a perceived polarization (e.g. Simon, Reininger, Schaefer, Zitzmann, \& Krys, 2018; see also Sarrasin, Green, \& Van Assche, 2019 on the impact of immigrant integration policies and polarization). We make a novel contribution by examining whether and why perceptions of polarization link to both actual mobilization and intentions to engage in collective action (theoretical model summarized in Fig. 1). More specifically, we contend that perceived cleavage regarding immigration issues relates to a willingness to mobilize (path a). In other words, the more people conceive society as polarized regarding immigration issues, the more they will mobilize in line with their attitudes. Van Boven, Judd, and Sherman (2012)) state that "perceptions of political polarization can serve as a "call to action," increasing the likelihood of civic action" (p. 96). Furthermore, Simon and Klandermans (2001) suggest that perceptions of shared grievances and of power struggles between antagonistic groups promote engagement in collective action (see also Klandermans, 2014). By definition, perceived social polarization is linked to the perception that two groups with opposing grievances about a social issue are in a power struggle. This perception of polarization should therefore relate to greater intentions to participate in collective action.

Moreover, we suggest that this effect can be explained by two interrelated and well-established antecedents of collective action: identification and perceived efficacy (van Zomeren, Postmes, \& Spears, 2008). Indeed, perceived polarization within the society should relate to a social categorization process, influencing how important immigration attitudes are for individuals' self-definition and thereby believing oneself capable of making a change, which in turn triggers collective action. We first outline a theoretical model and then present three studies.

\section{The effect of perceived polarization through social identity}

Perceived pro- or anti-immigration climates affect immigration attitudes endorsed by citizens through a social conformity process (Falomir-Pichastor, Chatard, Selimbegovic, Konan, \& Mugny, 2013). Perceived polarization of these climates should also influence the function fulfilled by immigration attitudes for one's sense of self. Related to value-expressive (Katz, 1960) or social-adjustment (Smith, Bruner, \& White, 1956) functions, an attitude is self-defining when it is personally relevant and important, and thus defines individuals' sense of self (see Zunick, Teeny, \& Fazio, 2017). We contend that polarization makes salient the self-definition function of immigration attitudes (path $b$ in Fig. 1): Perceiving a polarized climate should allow people to define their self-concept, which in turn should motivate them to take action. Indeed, perceived polarization per se implies awareness that society is divided into (at least) two distinctive and diametrical opposite groups. By increasing the perception of differences between distinctive groups and similarities within these groups, polarization should foster a process of social categorization (Oakes, Turner, \& Haslam, 1991). This process plays a critical role when individuals define themselves. When a social category is accessible and salient, individuals will deem these categories as clear cues defining who they are (Oakes et al., 1991). By differentiating between people holding a pro- versus anti-immigration stance, polarization should therefore increase the salience of these attitudes and incite individuals to consider their opinions regarding immigration as a key factor defining their identity. Self-defining attitudes have proven to be particularly predictive of behaviour (Petty \& Krosnick, 1995). For instance, Zunick et al. (2017) showed that self-definition is related to intentions to spontaneously advocate in favor of a self-defining attitude. As a consequence, we expect that the more immigration attitudes are considered as self-defining, the more individuals will have intentions to act in line with their attitudes (path $c$ in Fig. 1). Moreover, this process of social categorization should also promote the perceptions of effectiveness of collective action.

\section{The effect of perceived polarization through collective efficacy}

According to resource mobilization theory, "collective action is a strategic and political enterprise rather than a passionate response to felt injustices" (van Zomeren et al., 2008, p. 506). Individuals should thus be motivated to engage in collective action when they anticipate that collective action is effective in achieving its goal (Klandermans, 1984). Believing their group is able to make societal change, that is collective efficacy, involves a sense of personal or collective power (Drury \& Reicher, 2005). The link between polarization, feelings of efficacy and social mobilization has for decades attracted the attention of scholars from political science. It has been argued that distinctiveness of political parties has important implications on citizens' political participation and voting behaviour (Committee on Political Parties APSA, 1950). However, research has mainly focused on actual (and not perceived) polarization and provided mixed results. Some studies suggest that actual polarization increases citizens' political participation by providing clear

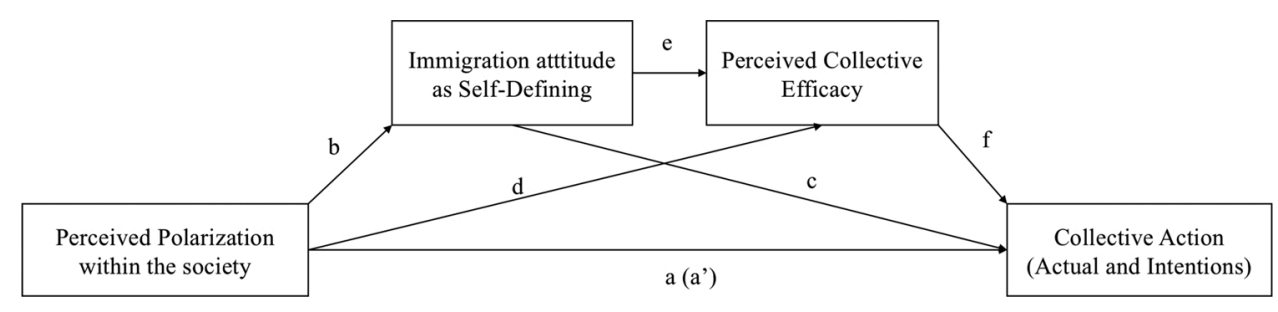

Fig. 1. Mediational model of the effect of perceived polarization on collective action (actual and intentions). 
partisan cues and policies representing their attitudes (e.g. Lachat, 2008; Thornton, 2013), while others show that citizens with moderate or unclear political attitudes disengage due to increasing political conflict resulting from political polarization (Rogowski, 2014). Analyzing cross-sectional data from American National Election Studies from 1972 to 2012, Enders and Armaly (2018) recently showed that perceived polarization between the Democratic and Republican party was positively related to voting, participation and efficacy. These results are consistent with the idea that the perceived effectiveness is promoted by the perception that others also share the same grievances (Simon \& Klandermans, 2001). We therefore expect that the perception of a cleavage on immigration issues within the society is related to a greater feeling of collective efficacy (path $d$ in Fig. 1).

Moreover, as mentioned above and because social identity empowers individuals (Mummendey, Kessler, Klink, \& Mielke, 1999), the link between perceived polarisation and feelings of efficacy should be, at least partially, explained by the central function taken by immigration attitudes in the individual's self-definition (path $e$ in Fig. 1). Finally, research has indeed provided extensive empirical support for the idea that subjective experiences of collective efficacy facilitate involvement in collective actions (e.g. van Zomeren et al., 2008) (path $f$ in Fig. 1).

\section{Current study}

Summarizing the argumentation above, the mediational model in Fig. 1 depicts how perceived polarization on immigration issues shapes mobilization both through collective action and political activism related to migration. To test our predictions, we conducted three studies among three different populations in two countries. In Study 1, we conducted a survey among highly mobilized Belgians participating in a citizen movement (i.e. "Plateforme citoyenne de soutien aux réfugiés"), which provides assistance to migrants in Brussels (i.e. mainly hosting and distribution of food and clothing) and was de facto one of the main political actors taking part in the political protest against the restrictive federal immigration policies (Vandevoordt, 2019). This study allowed us to investigate the effect of perceived polarization of immigration attitudes on their political activism and the role played by perceived efficacy among people highly involved in social movement (see Fig. 1, paths $d$ and f). In Study 2, conducted with a sample of Swiss university students, we tested whether the effect of perceived polarization replicates with a non-mobilized population and with the intention to engage in future collective action as dependent variable. Moreover, we included both theorized mediator variables (Immigration attitude as self-defining and Perceived collective efficacy) to test the indirect effects presented in Fig. 1. In Study 3, we test the same model of serial mediation among Belgian students with an experimental design to reveal causal links between the perception of polarization, both our mediators and the intention to mobilize.

\section{Study 1}

\section{Method}

\section{Participants}

Two hundred and twenty-four volunteers of a Belgian citizen movement in Brussels completed an online questionnaire. The questionnaire was disseminated on the Facebook pages of the citizen movement by the research team and by coordinators of the movement. Only people who had provided humanitarian assistance to migrants at least once were included in this sample.

\section{Measures}

\section{Perceived polarization about immigration}

Based on a measure developed by Van Boven, Judd and Sherman (2012), participants estimated the relative frequency of Belgian citizens' attitudes toward immigration. Specifically, participants were asked to estimate the percentage of the entire Belgian population responding "strongly oppose" "slightly oppose" "slightly favour" and "strongly favour" to the statement:" The number of migrants entering Belgium illegally must be limited". The sum of the percentages had to equal $100 \%$.

As Van Boven et al. (2012), we computed two different scores based on respondents' estimated distribution: perceived mean and polarization of attitudes. First of all, to calculate the average perceived attitude of Belgian people toward immigration, we weighted each response option ( $1=$ strongly oppose, $\mathrm{x}_{1} ; 2=$ slightly oppose, $\mathrm{x}_{2} ; 3=$ slightly favour, $\mathrm{x}_{3} ; 4=$ strongly favour, $\mathrm{x}_{4}$ ) by the percentage associated with that option. Perceived mean values could therefore range between 1 and 4. High numbers reflected participants' perception that Belgian people have on average positive attitudes toward immigration. Perceived mean is used in this study as a control variable. To illustrate our operationalization, presume that the percentages indicated by a participant for each option were $35 \%$ of « Belgian people are strongly opposed to immigration », $20 \%$ are slightly opposed, $15 \%$ are slightly in favour, and $30 \%$ are strongly in favour. The perceived mean would be $2.4:([1 \times .35]+[2 \times .20]+[3 \times .15]+[4 \times .30])$. Second, we calculated the perceived polarization. Van Boven et al. (2012) suggest using the standard deviation of each distribution around the middle of the scale. This calculation provides the absolute weight of extreme values of the scale but does not discriminate between a distribution where the entire population is perceived as highly opposed to immigration, and a divided population where half are perceived as highly opposed and the other half as extremely in favour. Because we are interested in the relative distribution around the middle of the scale, we multiplied the square roots of the perceived distribution deviation on one side of the scale by the square roots of the perceived distribution deviation on the other side. 
Perceived Polarization $=\sqrt{\left(2^{2} \mathrm{x}_{1}+1^{2} \mathrm{x}_{2}\right)} \cdot \sqrt{\left(1^{2} \mathrm{x}_{3}+2^{2} \mathrm{x}_{4}\right)}$

In this approach, if a participant perceives that the entire population holds negative (or positive) attitudes, and therefore that the society is unanimous and not polarized, he or she will have a score of 0 . Indeed, as the proportion of positive (or negative) people in the society is equal to 0 , one of the multiplication factors will also be equal to 0 . On the contrary, if a participant considers that society is divided into two equal groups that are respectively very unfavourable and very favourable, he or she will have a maximum polarization score of 2. Following the same response example as above, the perceived polarization would be 1.47:

$$
1.47=\sqrt{\left(\left(2^{2} \cdot 0,35\right)+\left(1^{2} \cdot 0,20\right)\right)} \cdot \sqrt{\left(\left(1^{2} \cdot 0,15\right)+\left(2^{2} \cdot 0,30\right)\right)}
$$

\section{Political activism}

We asked participants whether or not they had participated in four different political actions supporting the reception of migrants or migration policies in Belgium in the last six months (i.e. sign a petition; take part in a public demonstration; give or share a political opinion on social media; organize or participate in a political debate with local political stakeholders). If a participant took part in all four political actions, a score of 1 was allocated, 0.75 for three actions, 0.5 for two actions, 0.25 for one action, and 0 if they had not participated in any action.

Perceived collective efficacy

We used a single item: «I think that the Citizens Platform's mobilization has a significant impact on the migrants' living situation in Brussels » measured on 4-point scales ranging from 1 (Don't agree at all) to 4 (Totally agree).

\section{Results}

Bivariate correlations

As expected, perceived polarization $(M=1.07 ; S D=0.27)$ was positively related to volunteers' political activism $(M=.73 ; S D=$ $.24), r=.15, p=.03$. However, perceived collective efficacy $(M=2.95 ; S D=0.75)$ correlated with neither perceived polarization $(r=.04, p=.59)$ nor political activism $(r=-.06, p=.34)$.

\section{Mediation analysis}

Using the PROCESS macro (Hayes, 2012, Model 4), we tested the mediational model presented: Perceived Polarization was the independent variable, Perceived Efficacy was the mediator and Political Activism was the dependent variable (see paths $a$, $d$ and $\mathrm{f}$ in Fig. 1). As expected, Perceived Polarization had a significant positive effect on Political activism (see Table 1). However, Perceived Polarization had no effect on Perceived Collective Efficacy, $95 \%$ CI $[-0.26,0.49]$. The total effect of the model was significant, $95 \%$ CI $[0.01,0.26]$.

\section{Discussion}

Study 1 showed, among highly mobilized people, that the more the society is perceived as polarized, the more they will be involved in political activism. We replicate the positive correlation between the perception of a political polarization and political participation effect revealed notably by Enders and Armaly (2018) and suggested by Simon and Klandermans (2001). However, while we predicted that this effect could be explained by heighten perceived collective efficacy, we found no relation between sense of collective power

Table 1

Results for mediation model explaining the effect of Perceived Polarization on Political Activism (Study 1).

\begin{tabular}{llll}
\hline $\begin{array}{l}\text { Total Effect } \\
\text { Perceived Polarization to Political Activism (a) }\end{array}$ & 0.14 & 0.06 & 0.06 \\
$\begin{array}{l}\text { Direct Effect } \\
\text { Perceived Polarization to Political Activism (a') }\end{array}$ & 0.14 & $0.01,0.26]$ \\
$\begin{array}{l}\text { Path from IV to Mediator } \\
\text { Perceived Polarization to Perceived Efficacy (d) }\end{array}$ & 0.12 & 0.02 \\
$\begin{array}{l}\text { Path from mediator to DV } \\
\text { Perceived Efficacy to Political Activism (f) }\end{array}$ & -0.02 & {$[-0.26,0.49]$} \\
$\begin{array}{l}\text { Indirect Effects } \\
\text { Mediation through Perceived Efficacy }\end{array}$ & & 0.01 \\
\hline
\end{tabular}

Note. $N=224$.

Bootstrap samples $=5000$. Mean perception of the normative climate was included as control variable and did not have any significant effect on either the mediator or the DV. 
and the perception of a cleavage inside society. The item used to measure collective efficacy may explain this lack of effect: It relates to the perceived effectiveness of the citizen movement in influencing the living situation of migrants. However, political activism is linked to broader actions aiming at influencing public opinion and power struggles within society (Simon \& Klandermans, 2001). To overcome this limitation, in the next two studies, we used a validated scale tapping perceived ability to influence public opinion and power struggles.

Although we found support for the perceived polarization - activism link, the methodological choices in Study 1 involve further shortcomings. First of all, the participants were highly involved in a social movement taking part in advocacy and political activities, which aim at challenging immigration policies in place. Therefore, we need to ensure that the effect of perceived polarization replicates among a less mobilized population. Secondly, we need to further investigate the psychological process underlying political activism. According to the rationale outlined in the introduction, we hypothesized that the degree to which immigration attitudes are self-defining could play a critical role in mobilizing people and could be predicted by perceived polarization within the society. For these reasons, we conducted two additional studies assessing intentions of collective action and the function fulfilled by immigration attitudes among a priori less mobilized samples (i.e. university students). Since the samples included people with a wide range of attitudes toward migrants, these next two studies also allow extending our reasoning to people with both positive and negative attitudes toward immigration. This is why we controlled for the participants' attitude toward immigration.

\section{Study 2}

\section{Method}

\section{Participants}

Two hundred seventy-nine students attending an introductory social psychology course at a university in the French-speaking part of Switzerland completed the questionnaire (194 females; $M_{\text {Age }}=20.47, S D=3.08$ ).

\section{Measures}

Except when stated below, all variables were measured on 5-point scales ranging from 1 (Don't agree at all) to 5 (Totally agree).

Perceived polarization about immigration. We used the same measures as in Study 1, except that we included a fifth option in the middle of the scale "neither facilitate, neither limit" and the question was "Should Swiss migration policies limit or facilitate the access of foreigners to Swiss territory? What percentage of the Swiss population would like to strongly facilitate / facilitate / neither facilitate, neither limit / limit / strongly limit the access of foreigners to Swiss territory?".

Collective action intentions. We measured collective action intentions with a scale of four items developed by Van Zomeren, Spears, Fischer, and Leach (2004) (e.g., "I would participate in a demonstration to express my opinions on immigration"). This scale showed good reliability $(\alpha=.88)$.

Self-defining self-report measure. Based on Zunick et al. (2017), we measure self-defining function of immigration attitudes with two items (e.g., "My opinion about immigration is an important part of my identity") ( $r=.59$ ).

Perceived group efficacy. We measured perceived group efficacy with a two-item scale developed by Van Zomeren et al. (2004) (e.g., "I am able to influence public opinion by mobilizing myself and others with the same positions on immigration as I do") ( $r=.52$ ).

Attitude toward immigration. To remain consistent with the measure of perceived polarization of attitudes toward immigration, we asked participants to provide their own view on the same question with a scale from 1 "Strongly limit the access of foreigners to Swiss territory" to 5 "Strongly facilitate the access of foreigners to Swiss territory".

\section{Results and discussion}

\section{Bivariate correlations}

As expected, the bivariate correlation was significant between perceived polarization $(M=0.79 ; S D=0.24)$ and collective action intentions $(M=3.02 ; S D=0.95), \mathrm{r}=.19, \mathrm{p}<.001$. Perceived polarization was also positively correlated to the perception that immigration attitudes are self-defining $(M=2.96 ; S D=1.09)(r=.19, p<.001)$, but not to perceived efficacy $(M=3.32$; $S D=0.84), r=.06, \mathrm{p}=.29$. Both perceived efficacy $(r=.36, p<.001)$ and immigration attitude as self-defining $(r=.46, p<.001)$ were positively related to collective action intentions.

\section{Serial mediation analysis}

Using the PROCESS macro (Hayes, 2012, Model 6), we tested a serial mediation model, as presented in Fig. 1: Perceived Polarization was the independent variable, Self-defining Attitude was the first mediator, Perceived Efficacy the second mediator and 
Collective Action Intentions was the dependent variable. Mean perception of the normative climate and Attitude toward immigration were included as control variables. Results showed that, as expected, Perceived Polarization had a significant positive effect on Self-defining Attitude (path $b$ ), which in turn had a significant positive effect on Perceived Efficacy (path $e$ ), which finally had a significant positive effect on Collective Action Intentions (path $f$ ); see Table 2). As in Study 1, the path between Perceived Polarization and Perceived Efficacy was not significant, $95 \%$ CI $[-0.41,0.40]$. We also hypothesized that the perceived polarization would lead individuals to consider their attitudes toward immigration as defining themselves, which would then fuel their sense of efficacy, which would ultimately encourage collective action intentions. As predicted, results showed that indirect effects through Self-Defining and through the two mediators (i.e. our serial mediation hypothesis) were both significant. Finally, the total effect of the model was also significant, $95 \%$ CI [0.05, 0.92].

\section{Study 3}

Though based on the first two studies of the present research, we suggest that the perception of a polarized society about immigration issues lead people to take action, past research has also evidenced the reverse path. Recently, Simon et al. (2018) showed that politicization promotes both affective and cognitive polarization. Zaal et al. (2015) also demonstrated that politicized actors tend to differentiate between potential allies and adversaries in the wider society, which leads them to perceive polarization of society. To investigate our directional causal sequence hypothesis, we conducted a third study experimentally manipulating the perception of polarization. Moreover, this third study is an opportunity to replicate Study 2 results showing that perceived polarization mainly influences the way individuals will identify themselves. Finally, we pre-registered this study and performed power analyses to define our sample size (see, https://osf.io/8k95n/).

\section{Method}

\section{Participants}

A Monte Carlo power analysis for indirect effects application was used to determine an appropriate sample size (Schoemann, Boulton, \& Short, 2017). This analysis revealed that we would need a sample of two hundred and fifty-seven participants to achieve .80 power, considering the correlations that we obtained in the Study 2. We recruited 369 French-speaking Belgian students in Brussels, Belgium. All participants completed the study online and received course credit. After excluding 96 participants who either did not have Belgian nationality or did not have any parents with Belgian nationality, 273 participants were included in the analyses reported below.

\section{Procedure}

Participants were randomly assigned to two experimental conditions by the online survey platform (i.e. Limesurvey). Participants were invited to read fictitious results of a survey on attitudes towards immigration carried out among the Belgian population. The results were presented in the form of a graph that was either polarized $(N=130)$ or representing a normal curve $(N=143)$. To

Table 2

Results for serial mediation model explaining the effect of perceived polarization on collective action intentions (Study 2).

\begin{tabular}{|c|c|c|c|}
\hline & $b$ & S.E. & $95 \%$ C.I. \\
\hline \multicolumn{4}{|l|}{ Total Effect } \\
\hline Perceived Polarization to Collective Action Intentions (a) & 0.49 & 0.22 & {$[0.05,0.92]$} \\
\hline \multicolumn{4}{|l|}{ Direct Effect } \\
\hline Perceived Polarization to Collective Action Intentions (a') & 0.31 & 0.20 & {$[-0.09,0.71]$} \\
\hline \multicolumn{4}{|l|}{ Path from IV to Self-defining Attitude } \\
\hline Perceived Polarization to Self-defining Attitude (b) & 0.60 & 0.26 & {$[0.09,1.10]$} \\
\hline \multicolumn{4}{|l|}{ Path from IV and Self-defining Attitude to Perceived Efficacy } \\
\hline Perceived Polarization to Perceived Efficacy (d) & -0.01 & 0.21 & {$[-0.41,0.40]$} \\
\hline Self-defining Attitude to Perceived Efficacy (e) & 0.14 & 0.05 & {$[0.04,0.23]$} \\
\hline \multicolumn{4}{|l|}{ Path from mediators to DV } \\
\hline Self-defining Attitude to Collective Action Intentions (c) & 0.27 & 0.05 & {$[0.17,0.36]$} \\
\hline Perceived Efficacy to Collective Action Intentions (f) & 0.26 & 0.06 & {$[0.14,0.38]$} \\
\hline \multicolumn{4}{|l|}{ Indirect Effects } \\
\hline Mediation through Self-defining Attitude & 0.16 & 0.08 & {$[0.01,0.32]$} \\
\hline Mediation through Perceived Efficacy & -0.01 & 0.06 & {$[-0.11,0.12]$} \\
\hline Serial mediation through both mediators & 0.02 & 0.01 & {$[0.01,0.06]$} \\
\hline
\end{tabular}

Note. $N=279$.

Bootstrap samples $=5000$. Mean perception of the normative climate was included as control variable, but was unrelated to the mediators and the DV. Attitude toward immigration was also included as control variable, and had a positive effect on both the mediators and the DV. 
reinforce the manipulation and to ensure accurate understanding, the graphs were followed by a short transcription of an interview with an expert describing the alleged situation (polarized or not). In both experimental conditions, the vignettes (i.e., the graph and the expert interview) indicated that the average level of attitude is neither positive nor negative (i.e., in the middle of the scale).

\section{Measures}

\section{Manipulation check}

We used two items to check the perception of polarization on immigration issues within the Belgian society: "Society in Belgium is very divided on the issue of immigration.", "There is a strong polarization in Belgium when it comes to immigration." ( $\mathrm{r}=.38$ ). We also checked the perceived mean of immigration attitudes within Belgian society with two items: "Belgian society is hostile to the arrival of new migrants." and "On average, society in Belgium has rather positive attitudes towards immigration."

Regarding the other variables (i.e. Collective action intentions, Self-defining self-report and Perceived group efficacy, Attitude toward immigration), we used exactly the same measures as in Study 2. All scales showed good reliability (Collective action intentions, $\alpha=.93$; Self-defining, $\mathrm{r}=.79$; Perceived group efficacy, $\mathrm{r}=.35$ ).

\section{Results and discussion}

\section{Bivariate correlations}

As expected, the bivariate correlations were significant between, on the one hand, the perception that immigration attitudes are self-defining $(M=3.94 ; S D=1.59)$ and, on the other hand, Perceived group efficacy $(M=4.30 ; S D=1.27),(r=.30, p<.001)$ and Collective action intentions $(M=3.95 ; S D=1.70), r=.31, p<.001$. Moreover, Perceived group efficacy was also positively correlated to collective action intentions, $r=.43, p<.001$.

\section{Manipulation check}

As predicted, participants perceived that the Belgian society is more polarized when they had to read the experimental vignette depicting the society as particularly divided $(M=4.00 ; S D=0.75)$ than when there were no cleavages in society $(M=3.56$; $S D=0.73), F(1,271)=23.51, p<.001, \eta 2=.08$. Moreover, there is no difference between the two conditions regarding their perception of the average level of attitudes in society (polarized condition: $M=3.09 ; S D=0.68$; unpolarized condition : $M=3.09$; $S D=0.69), F(1,271)=0.01, p=.94, \eta 2=.001$. Thus, the manipulation worked as planned.

\section{Serial mediation analysis}

Using the PROCESS macro (Hayes, 2012, Model 6), we tested a serial mediation model, presented in Fig. 1. Results showed that, as expected, Polarization vs. Unpolarized had a significant positive effect on Self-defining Attitude (path $b$ ), which in turn had a significant positive effect on Perceived Efficacy (path $e$ ), which finally had a significant positive effect on Collective Action Intentions

Table 3

Results for serial mediation model explaining the effect of polarization on collective action intentions (Study 3).

\begin{tabular}{|c|c|c|c|}
\hline & $b$ & S.E. & $95 \%$ C.I. \\
\hline \multicolumn{4}{|l|}{ Total Effect } \\
\hline Polarization to Collective Action Intentions (a) & 0.20 & 0.10 & {$[0.01,0.39]$} \\
\hline \multicolumn{4}{|l|}{ Direct Effect } \\
\hline Polarization to Collective Action Intentions (a') & 0.13 & 0.09 & {$[-0.05,0.31]$} \\
\hline \multicolumn{4}{|l|}{ Path from IV to Self-defining Attitude } \\
\hline Polarization to Self-defining Attitude (b) & 0.23 & 0.09 & {$[0.05,0.41]$} \\
\hline \multicolumn{4}{|c|}{ Path from IV and Self-defining Attitude to Perceived Efficacy } \\
\hline Polarization to Perceived Efficacy (d) & 0.02 & 0.07 & {$[-0.12,0.17]$} \\
\hline Self-defining Attitude to Perceived Efficacy (e) & 0.20 & 0.05 & {$[0.10,0.29]$} \\
\hline \multicolumn{4}{|l|}{ Path from mediators to DV } \\
\hline Self-defining Attitude to Collective Action Intentions (c) & 0.15 & 0.06 & {$[0.03,0.27]$} \\
\hline Perceived Efficacy to Collective Action Intentions (f) & 0.46 & 0.08 & {$[0.31,0.61]$} \\
\hline \multicolumn{4}{|l|}{ Indirect Effects } \\
\hline Mediation through Self-defining Attitude & 0.03 & 0.02 & {$[0.01,0.09]$} \\
\hline Mediation through Perceived Efficacy & 0.02 & 0.03 & {$[-0.06,0.08]$} \\
\hline Serial mediation through both mediators & 0.02 & 0.01 & {$[0.01,0.05]$} \\
\hline
\end{tabular}

Note. $N=273$.

Bootstrap samples $=5000$.

As in Study 2, Mean perception of the normative climate, included as control variable, was unrelated to the mediators and the DV. Attitude toward immigration was also included as control variable, but had a positive effect on both the mediators and the DV. 
(path $f$; see Table 3). As in Studies 1 and 2, the path between Polarization and Perceived Efficacy was not significant, $95 \%$ CI [-0.12, 0.17]. Results also replicated the finding of Study 2 regarding the significant indirect effects. Indeed, the indirect paths through Self-Defining attitude and through the two mediators consecutively were both significant. Finally, the total effect of the model was also significant, $95 \%$ CI [0.01, 0.39]. These results demonstrate once again the influence of the perception of polarization on individuals' intentions to mobilize and the central role played in this effect by the self-defining function of immigration attitudes.

\section{General discussion}

Across three studies we showed that perceiving society as divided on immigration issues related to actual political activism (Study 1) and intentions to engage in collective action (Study 2 and Study 3). This result supports the idea that perceiving polarization within the society plays an important role in mobilizing people in line with their attitudes. This is consistent with seminal works in social psychology, such as those of Sherif and Hovland (1961), stressing that individuals evaluate social issues according to attitudes they perceive in their social environment. Moreover, while a more recent literature has so far shown that perceptions of polarization within society are the consequence of earlier mobilization (e.g. Simon et al., 2018), our research suggests the opposite pattern and argues that the perception of polarization is also a predictor of collective action. Employing an experimental vignette method in Study 3, we contribute to the existing literature by providing evidence regarding the causality of this effect: Perceived social polarization on immigration issue led to engagement in collective action.

Our research also examined the process explaining the link between perceived polarization and collective action. We make a novel contribution (Studies 2 and 3) by showing that conceiving the political climate as polarized defines individuals' self-concept, which in turn motivates mobilization. In other words, the mobilizing effect of perceived cleavage within the society was partially explained by a heightened conception of immigration attitudes fulfilling a self-identification function. Moreover, we demonstrated that the more immigration attitudes were considered self-defining, the more individuals intended to act in line with their attitudes. These results are in line with Zunick et al. (2017) who showed that people tend to take part in advocating actions in favor of a self-defining attitude.

Regarding the role of perceived efficacy, we found contrasting results. First of all, except in Study 1 (likely due to the measurement of collective efficacy), we found evidence to the well-established contention in collective action and political behavior literature that perceived collective efficacy predicts individuals' tendency to act (e.g. van Zomeren et al., 2008). However, we found no link between perceived polarization and perception of collective efficacy. Research on this issue has yielded mixed results (e.g. Rogowski, 2014; Enders \& Armaly, 2018). One possible explanation is that the more society is perceived to be polarized, the more people are perceived to have extreme attitudes, and therefore less likely to be influenced by collective actions conveyed by the antagonistic group opinion. This interpretation is in line with Simon and Klandermans' (2001) suggestion to go beyond an analysis of simple bipolar intergroup relations and also take into account the role of a third party (i.e., people who do not belong to either of the two antagonistic groups). The objective of collective actions in contexts shaped by power struggles is to take control of this third group. However, the more polarized society becomes, the less it is possible to influence these people and, therefore, collective actions are perceived less effective. The notion of "multiorganizational fields" (Curtis \& Zurcher, 1973) provides another avenue of interpretation. Indeed, in the social environment, there are multiple organizations with which social movements can interact. These organizations are structured in systems of alliance and conflict. According to Klandermans (1993), a multiorganizational field characterized by a strong and extensive conflict system, such as in a highly polarized society, tends to inhibit mobilization potential. Future research should investigate these issues by assessing (or experimentally manipulating) systems of conflict and alliances operating within the fields of mobilization.

More generally, future research should seek to uncover contexts in which polarization leads to citizen empowerment. Indeed, the perception of polarization on migration issues predicted the feeling that attitudes about immigration are constitutive of the selfidentity, which ultimately influenced the perception of being able to influence public opinion and power relations on migration issues within society. This indirect effect highlights the predominant role of identity dynamics in the social psychological processes linked to perceiving polarization and, more broadly, to those leading individuals to mobilize. However, while our studies show effects of perceived polarization related to migration issues, future studies could also examine whether this pattern replicates for other societal issues (e.g., gender equality or environmental issues). Future research could also extend our results by investigating the influence of perceived polarization on participation in radical or non-normative actions (e.g., Becker \& Tausch, 2015). Indeed, radical action is qualitatively different from non-radical, more conventional political actions (e.g., Tausch et al., 2011). In particular, some studies show the importance of identification processes underlying non-normative engagement (e.g. Becker, Tausch, Spears, \& Christ, 2011).

In the context where immigration divides the political spaces of Western societies, our results highlight possible interpretations of the strong mobilizations that have emerged since 2015 following the so-called migrant crisis (Rea, Mazzola, Martiniello, \& Meuleman, 2019). Bringing together our study and the research of Simon et al. (2018) points to a vicious circle where the perception of polarization leads to more politicization of individuals, which in turn leads to more polarization. Future research should seek to understand the moderating factors of this loop to curb a sharp increase in polarization.

\section{Acknowledgements}

This work was supported by the Swiss National Science Foundation National Center of Competence in Research nccr - on the move (grant number 51NF40-142020) and by the Fédération Wallonie Bruxelles, Belgium - ARC (Untangling the multiple categorizations of migrants. Intersectional Frameworks and Practices). 


\section{References}

Allport, G. W. (1954). The nature of prejudice. Reading, MA: Addison-We.

Becker, J. C., \& Tausch, N. (2015). A dynamic model of engagement in normative and non- normative collective action: Psychological antecedents, consequences, and barriers. European Review of Social Psychology, 26(1), 43-92. https://doi.org/10.1080/10463283.2015.1094265.

Becker, J. C., Tausch, N., Spears, R., \& Christ, O. (2011). Committed dis (s) idents: Participation in radical collective action fosters disidentification with the broader in-group but enhances political identification. Personality \& Social Psychology Bulletin, 37(8), 1104-1116.

Committee on Political Parties APSA. (1950). Toward a more responsible two-party system: A report of the committee on political parties. The American Political Science Review, 44(Supplement), 1-96.

Curtis, R. L., \& Zurcher, L. A. (1973). Stable resources of protest movements: The multiorganizational field. Social Forces, 52, 53-61.

della Porta, D. (Ed.). (2018). Solidarity Mobilizations in the 'Refugee Crisis.' https://doi.org/10.1007/978-3-319-71752-4.

Drury, J., \& Reicher, S. (2005). Explaining enduring empowerment: A comparative study of collective action and psychological outcomes. European Journal of Social Psychology, 35(1), 35-58.

Enders, A. M., \& Armaly, M. T. (2018). The differential effects of actual and perceived polarization. Political Behavior, 1-25. https://doi.org/10.1007/s11109-0189476-2.

Falomir-Pichastor, J. M., Chatard, A., Selimbegovic, L., Konan, P. N. D., \& Mugny, G. (2013). Conformity and counter-conformity to anti-discrimination norms: The moderating effect of attitude toward foreigners and perceived in-group threat. Journal of Applied Social Psychology, 43(2), 206-215. https://doi.org/10.1111/ jasp.12024.

Falomir-Pichastor, J. M., Muñoz-Rojas, D., Invernizzi, F., \& Mugny, G. (2004). Perceived in-group threat as a factor moderating the influence of in-group norms on discrimination against foreigners. European Journal of Social Psychology, 34(2), 135-153. https://doi.org/10.1002/ejsp.189.

Fasel, N., Green, E. G. T., \& Sarrasin, O. (2013). Unveiling naturalization: A multilevel study on minority proportion, conservative ideologies, and attitudes toward the Muslim Veil. Zeitschrift Fur Psychologie / Journal of Psychology, 221(4), 242-251. https://doi.org/10.1027/2151-2604/a000154.

Hayes, A. F. (2012). PROCESS: A versatile computational tool for observed variable mediation, moderation, and conditional process modeling.

Katz, D. (1960). The functional approach to the study of attitudes. Public Opinion Quarterly, 24(2), 163. https://doi.org/10.1086/266945.

Klandermans, B. (1984). Mobilization and participation: Social-psychological expansisons of resource mobilization theory. American Sociological Review, 49(5), 583-600.

Klandermans, B. (1993). A theoretical framework for comparisons of social movement participation. Sociological Forum, 8, $383-402$.

Klandermans, B. (2014). Identity politics and politicized identities: Identity processes and the dynamics of protest. Political Psychology, $35(1), 1-22$.

Kriesi, H., Grande, E., Lachat, R., Dolezal, M., Bornschier, S., \& Frey, T. (2006). Globalization and the transformation of the national political space: Six European countries compared. European Journal of Political Research, 45(6), 921-956. https://doi.org/10.1111/j.1475-6765.2006.00644.x.

Lachat, R. (2008). The impact of party polarization on ideological voting. Electoral Studies, 27(4), 687-698. https://doi.org/10.1016/j.electstud.2008.06.002.

Mummendey, A., Kessler, T., Klink, A., \& Mielke, R. (1999). Strategies to cope with negative social identity: Predictions by social identity theory and relative deprivation theory. Journal of Personality and Social Psychology, 76(2), 229-245.

Oakes, P. J., Turner, J. C., \& Haslam, S. A. (1991). Perceiving people as group members: The role of fit in the salience of social categorizations. The British Journal of Social Psychology, 30, 125-144.

Petty, R. E., \& Krosnick, J. A. (1995). Attitude strength: Antecedents and consequences. Mahwah, NJ: Erlbaum As.

Rea, A., Mazzola, A., Martiniello, M., \& Meuleman, B. (2019). The refugee reception crisis in Europe. polarized opinions and mobilizations. Bruxelles: Editions de l'Université de Bruxelles. https://doi.org/10.26530/OAPEN_1005529.

Rogowski, J. C. (2014). Electoral choice, ideological conflict, and political participation. American Journal of Political Science, 58(2), 479-494. https://doi.org/ 10.1111/ajps.12059.

Sarrasin, O., Green, E. G., \& Van Assche, J. (2019). Consensual versus heterogeneous conceptions of nationhood: The role of citizenship regimes and integration policies across 21 European countries. Social Indicators Research, 1-18.

Schoemann, A. M., Boulton, A. J., \& Short, S. D. (2017). Determining power and sample size for simple and complex mediation models. Social Psychological and Personality Science, 8(4), 379-386. https://doi.org/10.1177/1948550617715068.

Sherif, M., \& Hovland, C. I. (1961). Social judgment: Assimilation and contrast effects in communication and attitude change. New Haven, CT: Yale University Press.

Simon, B., \& Klandermans, B. (2001). Politicized collective identity: A social psychological analysis. The American Psychologist, 56(4), 319.

Simon, B., Reininger, K. M., Schaefer, C. D., Zitzmann, S., \& Krys, S. (2018). Politicization as an antecedent of polarization: Evidence from two different political and national contexts. The British Journal of Social Psychology. https://doi.org/10.1111/bjso.12307.

Simsa, R. (2017). Leaving emergency management in the refugee crisis to civil society? The case of Austria. Journal of Applied Security Research, 12(1), 78-95. https:// doi.org/10.1080/19361610.2017.1228026.

Smith, M., Bruner, J., \& White, R. (1956). Opinions and personality. New York, NY: John Wiley.

Strijbis, O., Helmer, J., \& de Wilde, P. (2018). A cosmopolitan-communitarian cleavage around the world? Evidence from ideological polarization and party-voter linkages. Acta Politica. https://doi.org/10.1057/s41269-018-0122-0.

Tausch, N., Becker, J. C., Spears, R., Christ, O., Saab, R., Singh, P., et al. (2011). Explaining radical group behavior: Developing emotion and efficacy routes to normative and nonnormative collective action. Journal of Personality and Social Psychology, 101(1), 129.

Thornton, J. R. (2013). The impact of elite polarization on partisan ambivalence and indifference. Political Behavior, 35(2), 409-428. https://doi.org/10.1007/ s11109-012-9196-y.

Van Boven, L., Judd, C. M., \& Sherman, D. K. (2012). Political polarization projection: Social projection of partisan attitude extremity and attitudinal processes. Journal of Personality and Social Psychology, 103(1), 84-100. https://doi.org/10.1037/a0028145.

van Zomeren, M., Postmes, T., \& Spears, R. (2008). Toward an integrative social identity model of collective action: A quantitative research synthesis of three sociopsychological perspectives. Psychological Bulletin, 134(4), 504-535. https://doi.org/10.1037/0033-2909.134.4.504.

Van Zomeren, M., Spears, R., Fischer, A. H., \& Leach, C. W. (2004). Put your money where your mouth is! Explaining collective action tendencies through group-based anger and group efficacy. Journal of Personality and Social Psychology, 87(5), 649-664. https://doi.org/10.1037/0022-3514.87.5.649.

Vandevoordt, R. (2019). Eroding rights, crafting solidarity? Shifting dynamics in the state-civil society Nexus in Flanders and Brussels. Social Inclusion, 7(2), 106. https://doi.org/10.17645/si.v7i2.2010.

Visintin, E. P., Green, E. G. T., Falomir-Pichastor, J. M., \& Berent, J. (2019). Intergroup contact moderates the influence of social norms on prejudice. Group Processes \& Intergroup Relations. https://doi.org/10.1177/1368430219839485.

Zaal, M. P., Saab, R., Brien, K. O., Jeffries, C., Barreto, M., \& Laar, C. V. (2015). You' re either with us or against us ! Moral conviction determines how the politicized distinguish friend from foe. Group Processes \& Intergroup Relations, 20(4), 519-539. https://doi.org/10.1177/1368430215615682.

Zunick, P. V., Teeny, J. D., \& Fazio, R. H. (2017). Are some attitudes more self-defining than others? Assessing self-related attitude functions and their consequences. Personality \& Social Psychology Bulletin, 43(8), 1136-1149. https://doi.org/10.1177/0146167217705121. 